\title{
An educational project for master's program in computing
}

\author{
Juliana Peneva, Stanislav Ivanov, Petko Staynov
}

\begin{abstract}
The curriculum of a specific master's program is discussed in thematic and methodological aspect. The general plan, the target group and the educational parameters of the program are represented. The features of the curriculum as thematic areas, learning activities and schedule are discussed. Some statistical data concerning the program implementation are also provided.
\end{abstract}

Key Words: master's program, computing, software technologies, information systems

\section{INTRODUCTION}

Currently, the industry more than ever is a customer of the sciences. This justifies the traditional view on masters' programs as producers of well trained specialists oriented towards research and development. At the same time the technology oriented activities also require a significant amount of knowledge and skills that can not be acquired along with a bachelor's study. Consider the field of information and communications technologies (ICT) exhibiting the growing up demand of knowledge and various computing skills. Especially education in computing is dynamic because of the advances in information technologies. Speeded development and deployment of these technologies impose adequate changes in curricula for all educational degrees. In addition the proper and immediate professional recognition of ICT graduated students determines the trend towards a pragmatic education. The acute shortage of ICT specialists results in the fact that human resources without proper education or vocational training are redirected ton computing. So, developing technologically centered education in computing is determined by social and economic factors, i.e. the workforce market. This is the reason masters' programs in software engineering (SE) and information systems (IS) to be preferred. Aiming to meet the needs of their students and those of the society as whole, academic institutions apply the so called "portfolio strategy" offering a diversity of specialized programs. Due to fiscal constraints, the new proposed programs should be economically justified and the efficiency is a predominant factor. The program under consideration is a new educational product which generally complies to the common scheme for masters' programs in computing [1],[2], at the same time exhibiting own specificity.

Following its motto Ne varietatem timeamus New Bulgarian University (NBU) gives prominence to innovation in its educational model. The mission of NBU is to provide general interdisciplinary and narrowly specialized education, based on research work and related to the practice. NBU determines its academic profile in the three priority fields, Natural sciences and new technologies being one of them. Education in Computer science in all degrees: bachelor, master and PhD conforms fully to this profile. Currently, NBU offers well-conducted programs for full-time study in computer science and network technologies [3]. The department of Informatics has developed:

- Bachelors' programs: 'Informatics', 'Network Technologies' (in English), 'Computer Media Technologies';

- Masters' Programs: 'Software Technologies for the Internet', 'Multimedia, Computer Graphic and Animation';

- a Doctoral Program: 'Theoretical Informatics'.

In this context the main focus of this paper is to discuss some didactic and methodic aspects that relate to the development of masters' programs in computing. We introduce the specific traits of the master's program 'Software Technologies for the Internet', the general plan, the target group and the educational parameters.

The rest of the paper is organized as follows. In Section 2, we present the program 
as an educational project. The features of the curriculum as thematic areas, learning activities and schedule are discussed in Section 3. Section 4 provides some statistical data concerning the program implementation and the users' interest in thematic areas. We summarize our results in Section 5.

\section{INTERNET' \\ 2. THE EDUCATIONAL PROJECT 'SOFTWARE TECHNOLOGIES FOR THE}

The coming of the master's program 'Software technologies for the Internet' is coupled with the formation of a totally new situation in the field of ICT through the increased Internet consumption of worldwide and national importance. This program represents an attempt to come after labor market trends. It can be viewed as result of NBU own progress in higher education as it concerns computer science. The program started in 1998 as a successor of two former masters' programs namely 'Computer Science' and 'Artificial Intelligence'. Actually these programs were the first educational products of the department of Informatics and their success was obvious - most of the students continued their study in doctoral programs abroad or joined leading national and foreign companies.

The necessity of technologically-centered education in computer science can be justified as follows:

- due to the very rapid development of ICT, the demand of knowledge and various computing skills is growing up and requires well-trained staff in all business and social activities;

- leading ICT companies prefer to enroll graduated computer science students, thus becoming the dominant consumer and provoking deficiency of human resources in the branch;

- in the labor market there is a proper niche for individuals with a different extent of training and diverse degrees in computer science;

- there is a trend for spontaneous re-direction in the ICT branch of educated persons from other branches and the needed re-qualification is on their own initiative;

- speeded development and deployment of ICT with Internet being the backbone, impose an adequate reorganization of all public activities under existing circumstances of the market economy.

Summarizing, there is a growing need of experts that would be involved to implement technological solutions in the software industry of its own as well as delivering information services in various application areas, e.g. insurance, finance, production, tourism, etc. This makes sense to launch corresponding education and to deliver specific masters' programs. It appears that a wide-input and pragmatic master's program should be oriented towards the target groups as:

- bachelors in Informatics whose official position and duties require higher qualification degree;

- higher education specialists that lack training in computer science but work in the ICT branch.

Such a solution has to satisfy the educational needs of a very large audience and to build competences of higher demand in different application domains. Viewing the Internetbased information services needs of the business and the wide practice of small and medium software enterprises as well, the following competences can be outlined:

- knowledge for: principles and functioning of the Internet; principles of the "client server" architecture and technology; main technological platforms for developing Internet applications;

- skills for: administration in local and global networks; specification of Internet-based software projects; development (individually or in a team) of Internet applications; management of small software projects.

Thus, the program has to be technologically centered. The master's program 'Software technologies for the Internet' aims these competency-based goals. Students show mastery 
of computer science knowledge and skills, through ability to develop web-enabled information systems and applications. They can work as effective individuals and as a part of a team to design and deliver quality software. Pursuing their specific interest students can further act as database or network administrators and project managers.

\section{FEATURES OF THE CURRICULUM}

At NBU we believe that the learning process should never stop, so we have a yearround open admission policy. The necessary documents are diploma for completed bachelor education and an essay on the topic "What opportunities do I foresee from studying Software Technologies for the Internet at NBU?" To enroll this program, evidences concerning the following competences are to be presented: literacy in mathematics, programming, algorithms and data structures, databases, computer architectures, networking, operating systems and web design. Candidate students that lack these competences have to take extra courses from the so-called preparatory module. The target group for this module comprises bachelors in economics, engineering, applied mathematics and natural sciences. As the program is technologically centered the learning content of the courses is upgraded every year to follow the advances in ICT. The agility in structuring this learning content is an important prerequisite for an increased interest to the program. Besides the traditional lecturing, non-auditoria educational forms such as internships, participation in scientific projects and technological developments are proposed. So, students make the best of their studies joining real time projects and doing research. Students' participation in scientific events is also highly encouraged. Last but not least NBU is equipped with the proper software - DBMS Oracle, Microsoft .NET, etc. that facilitates all teaching activities.

In addition lecturers are highly-regarded practitioners who share real-life experience and consider students as collaborative partners during the educational process. Courses are carefully designed to encourage self-directed learning with the focus on applying theory to practical experience.

The intensiveness of courses with the NBU is measured in credits. Credits are earned only upon positively graded academic load. A requirement for the completion of the pursued program is the accumulation of a certain number of credits. The average duration of studies within a master's program is a year and a half. The credit requirement for obtaining a master's degree is 105 - after obtaining a Bachelor's degree in computer science. Extra credits (30) are to be collected from students that lack the competences mentioned above. The curriculum is built up as follows:

1. Lectures- 21 elective courses, 30 hours and 3 credit each. Each term the students are supposed to choose 5 from the offered 7 disciplines and to collect 15 credits.

2. Non-auditoria educational forms:

- Self-dependent piece of work - 14 projects, 3 credit each. The students have to gather 30 credits by doing projects according to their interest.

- Internship - 15 credits

- Master's thesis - 15 credits

A working knowledge is acquired via the internship that has to be conducted in a real working environment - a software company, IT department, etc. The curriculum of the master's program 'Software technologies for the Internet' is presented in Table 1. Full description of the master's program can be found on the Web site of NBU [3].

\footnotetext{
I term

INFM 101 High-performance computer architectures

INFM 102 Computer security in the Internet

INFM 103 Information architectures for the Internet

INFM $111 \mathrm{PL} / \mathrm{SQL}$ programming

INFM 114 Script languages for the Internet

INFM 117 e-Business

INFM 119 Object-oriented programming for the Internet
} 


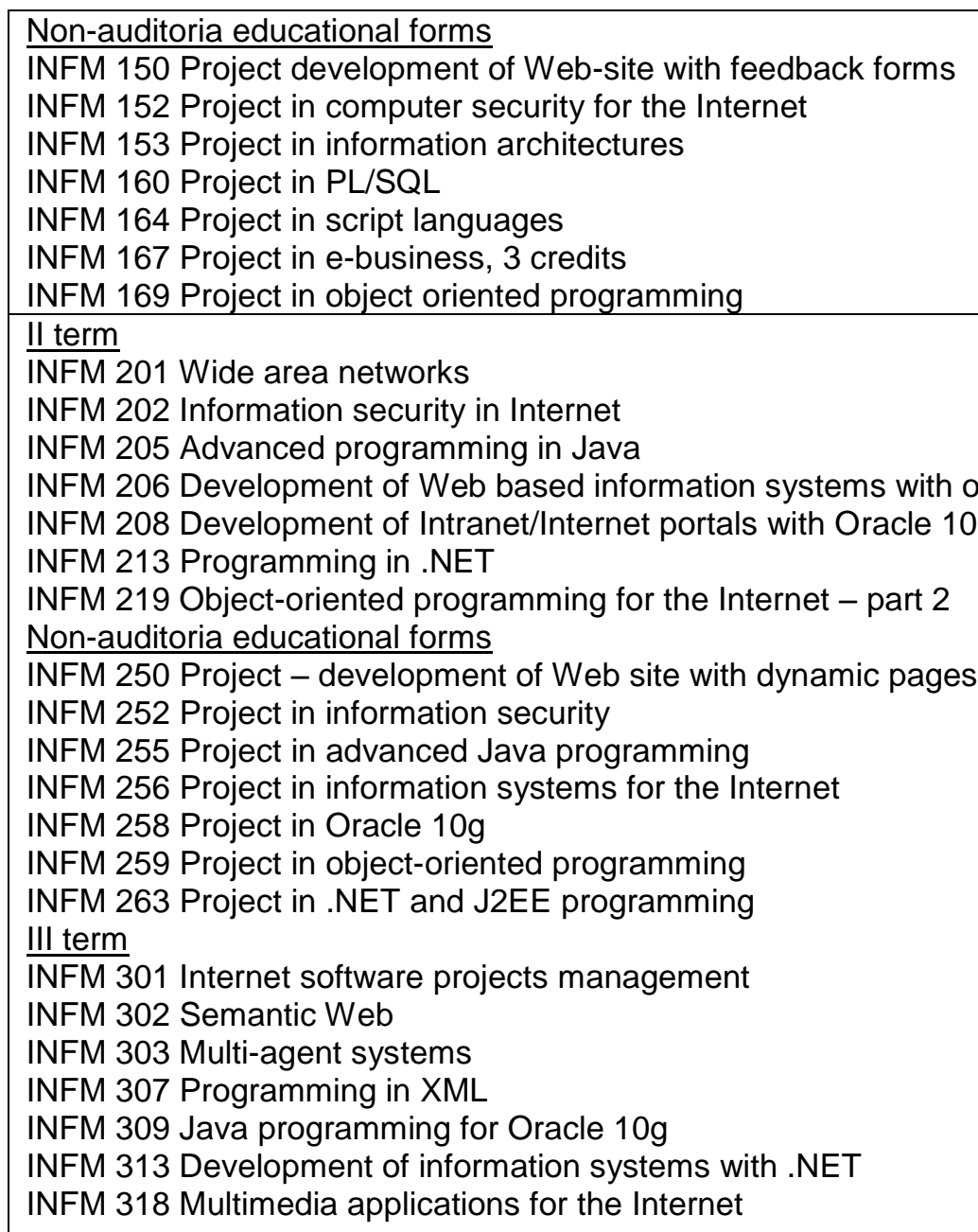

\section{Table 1}

\section{USERS' INTEREST IN THE MASTER'S PROGRAM}

The master's program 'Software technologies for the Internet' exists as an educational project for 8 years. During this period some data were collected in the University information system. Nevertheless the need analyses we try to perform in order to deliver the right educational product on the vast market, the analysis of these data help us monitor the user's interest. In this way we evaluate the program's effectiveness and significance and we are in a position to improve upon it.

The growth number of freshmen and the total number of students shows the increased interest toward the program (see Table 2).

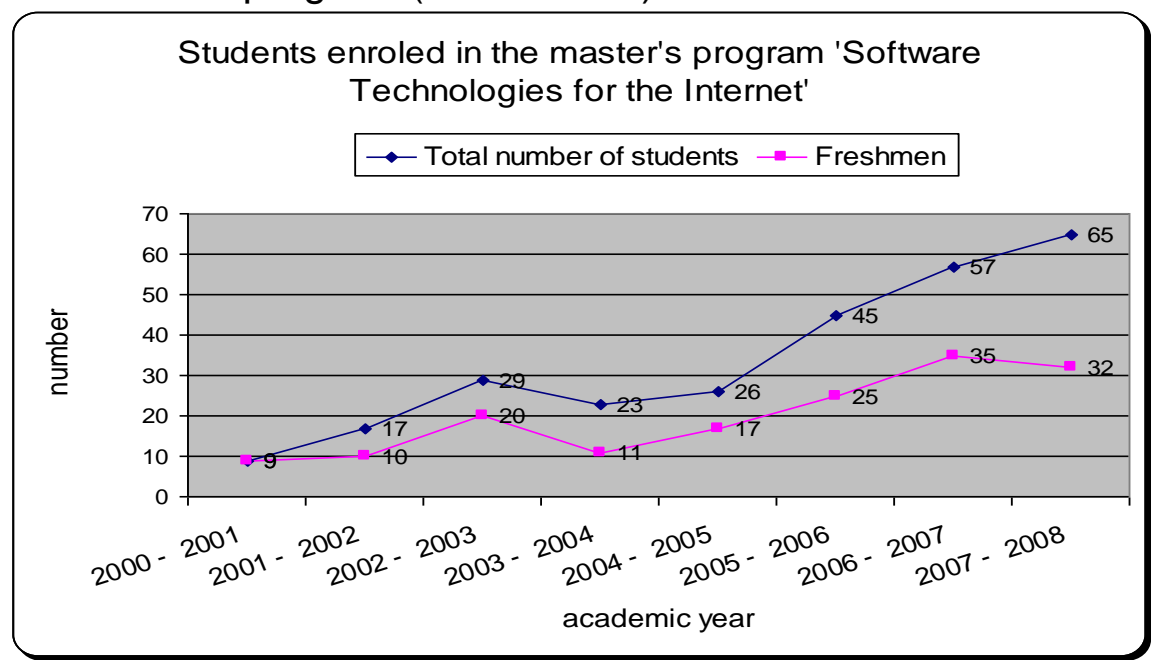

Table 2 
Table 3 shows the position of the program 'Software technologies for the Internet' compared to other masters' programs in NBU.

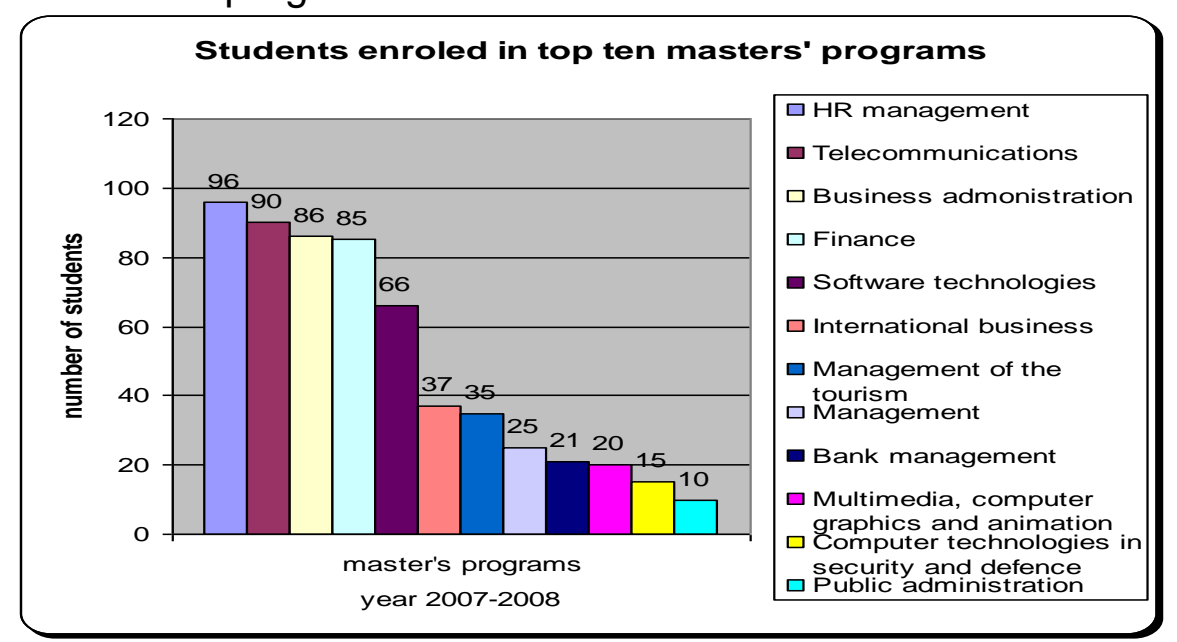

Table 3

All program courses are elective. Analyzing the number of the enrolled students in a particular course, enable us to judge of the distribution of the users' interest in subject areas. Prevailing interest in technologically centered courses is noticed (see Tables 3,4 and 5)

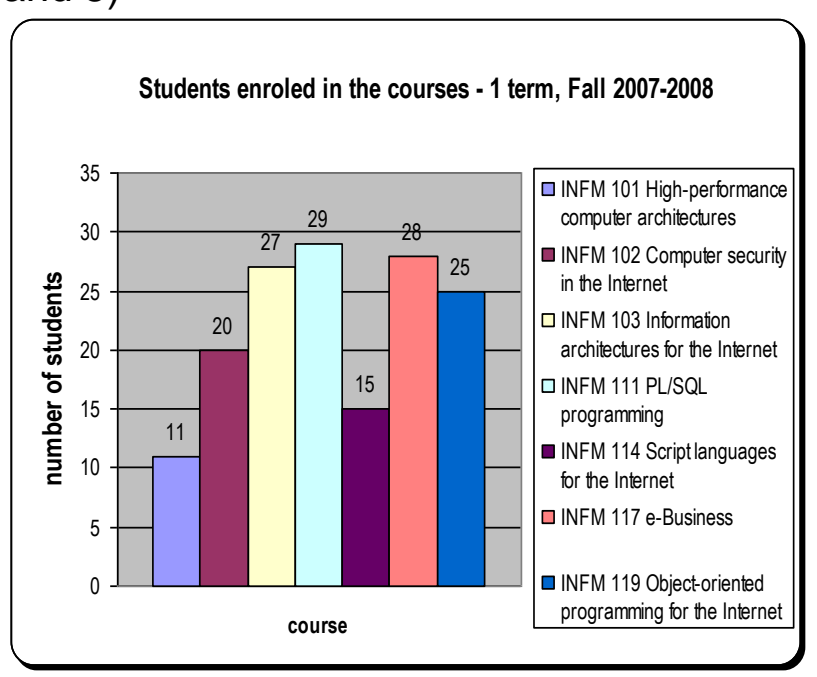

Table 3

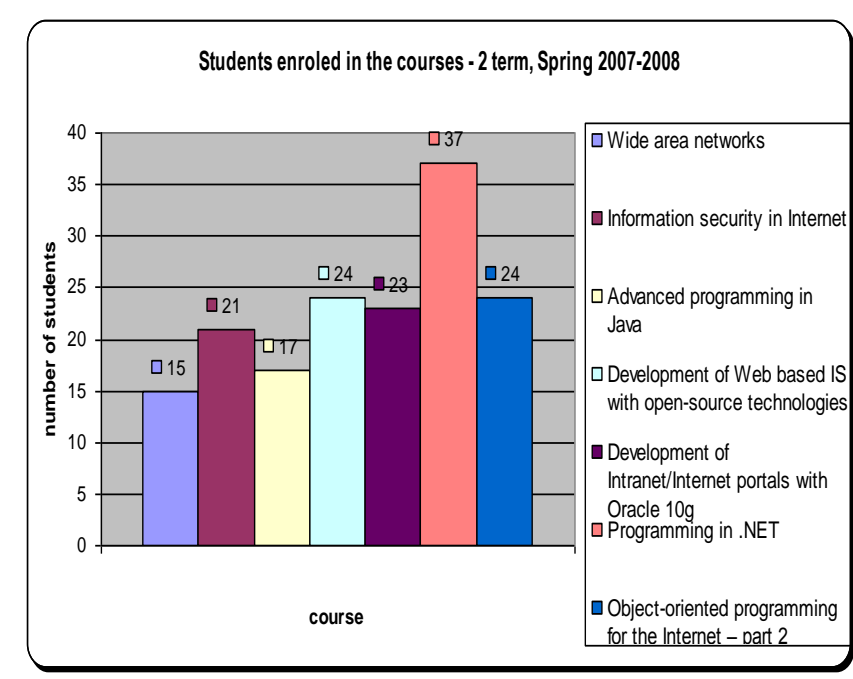

Table 4

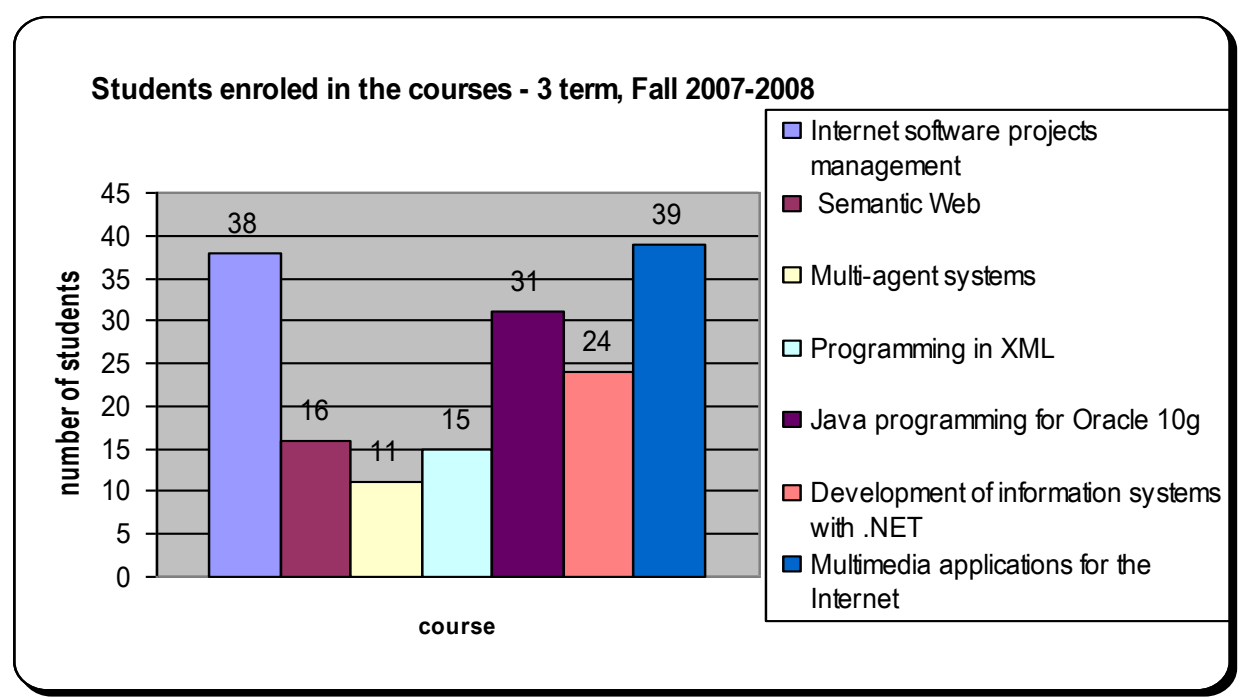

Table 5 
Most of our students are already working for significant national and foreign companies. Table 6 shows that the number of graduating students is fair.

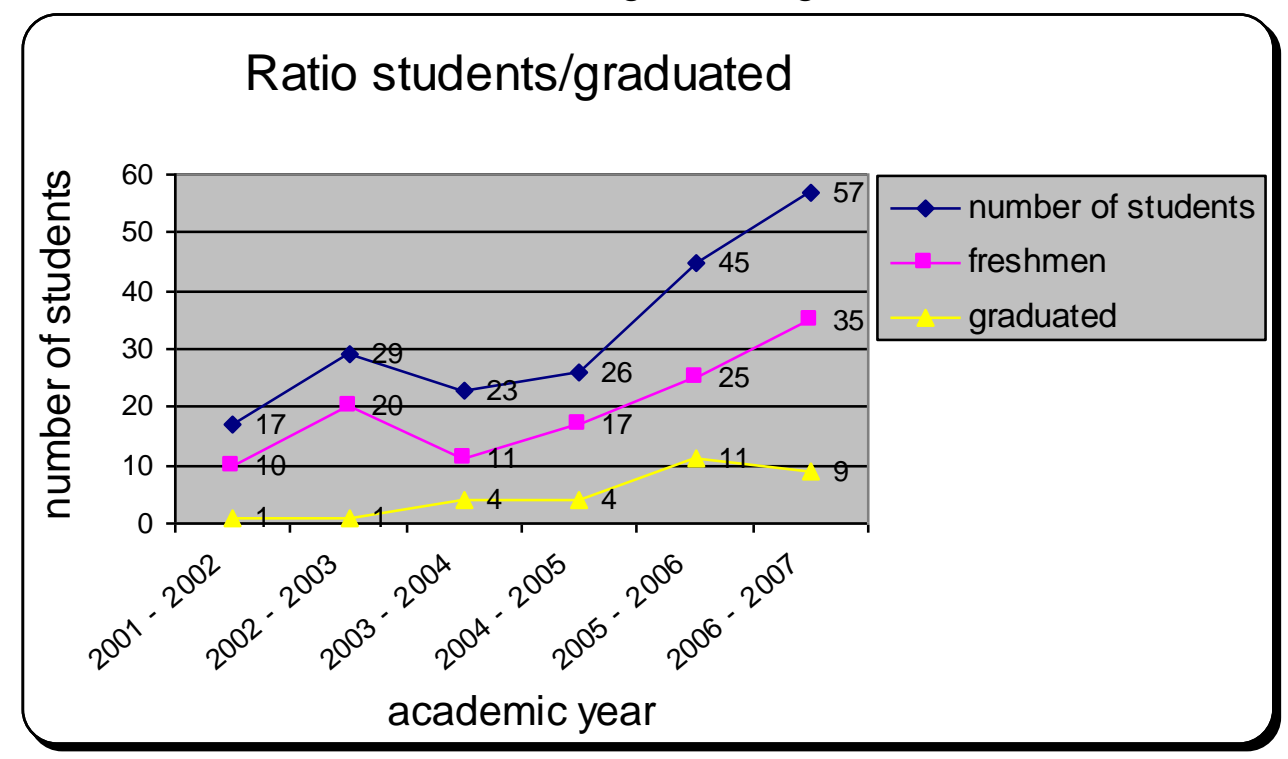

\section{CONCLUSIONS AND FUTURE WORK}

Table 6

The program discussed here is a specific, Web centered variant of master's program in the domain of software engineering. Some traditional for SE topics are omitted. Several courses concerning Web applications, Web based information systems and related technologies are added instead. From SE point of view some specific competences like testing and user interface are reduced or neglected. This program seems to be more than usual specialized. The advantage of this specialization is the gain of abilities, more suitable for the common practice in small software enterprises. Another advantage is the agility in adopting new technologies and platforms without changing the subject mastering Web based applications.

The development and offering of technologically centered masters programs in computer science is an advisable educational policy. In confirmation, a socially and economically motivated interest of the customers towards such kind of higher education is observed. The increasing admission, limited only by the lecturer's work load is an evidence for an active students' interest to this program. The sound personal motivations along with the live students' participation find expression in the excellent educational results of the graduated. The constant qualitative improvement of the admission is also a positive trend.

Going over the main points, our experience demonstrates that a technologically centered master's program in computing is promising.

\section{References:}

[1] Computing Curricula 2005. The overview report, ACM IEEE Computer Society, ISBN:1-59593-359-X

[2] http://ecet.ecs.ru.acad.bg/vedoc

[3] www.nbu.bg

\section{About the Authors:}

1. Assoc. Prof. Stanislav Ivanov, PhD New Bulgarian University, +359 2 811-0-611, sivanov@nbu.bg

2. Assoc.Prof.Juliana Peneva, PhD, New Bulgarian University, IMI - BAS +359 2 811-0-611, jpeneva@nbu.bg

3. Petko Staynov, New Bulgarian University,+359 2 811-0-610, pstaynov@nbu.bg This research is partially granted by Bulgarian National Science Fund, Ministry of Education and Sciences in the frame of the project "Technological and Didactical Issues of E-learning", contract N ВУ МИ-111/2005. 